\title{
Cultural Competence in the Eyes of Health Cluster Faculty Members at Qatar University: Perceptions and Applications- A Mixed Methods Study
}

\author{
Aicha Mohamed Ahmed ${ }^{1}$, Banan Mukhalalati ${ }^{2}$, Ahmed Awaisu $^{3}$ \\ ${ }^{1}$ College of pharmacy student ${ }^{2}$ Assistant Professor, \\ ${ }^{3}$ Associate Professor, College of Pharmacy, Qatar University
}

\section{Background}

Globalization is the growing interdependence of the world's cultures, populations and economies. (1)

Globalization impacts several aspects of life including education. This impact requires a full understanding of the concept of culture and cultural competence.

Medical education in Qatar is progressing by the effort of multicultural team that ensures the emerge of competent healthcare providers. (2)

Multicultural teaching can be beneficial in some area, but it can represent a challenge.

Qatar National Vision 2030 aims to achieve development progress, yet at the same time it aims to preserve national culture.

\section{(-) Objectives}

Investigate the perception of faculty members in Qatar University's (QU) Health Cluster (College of Pharmacy, Medicine, and Health Sciences) about cultural diversities among students and instructors and how they deal with these cultural diversities.

Examine the extent at which the educational programs in the Health Cluster adapt curricula content for cultural compatibility in terms of teaching.

S4 Methods

Study design:

Convergent mixed methods triangulation approach (3)(Figure 1).

Participant:

Faculty members of QU's Health Cluster.

Data collection

Quantitative:

Multicultural Teaching Competence Scale (MTCS)

questionnaire through SurveyMonkey®

Qualitative:

Three Focus groups were done using a topic guide.

Data analysis:

Quantitative: SPSS ${ }^{\circledR}$

Qualitative: NVIVOß

Ethical consideration:

IRB approval: QU-IRB 1109-EA/19

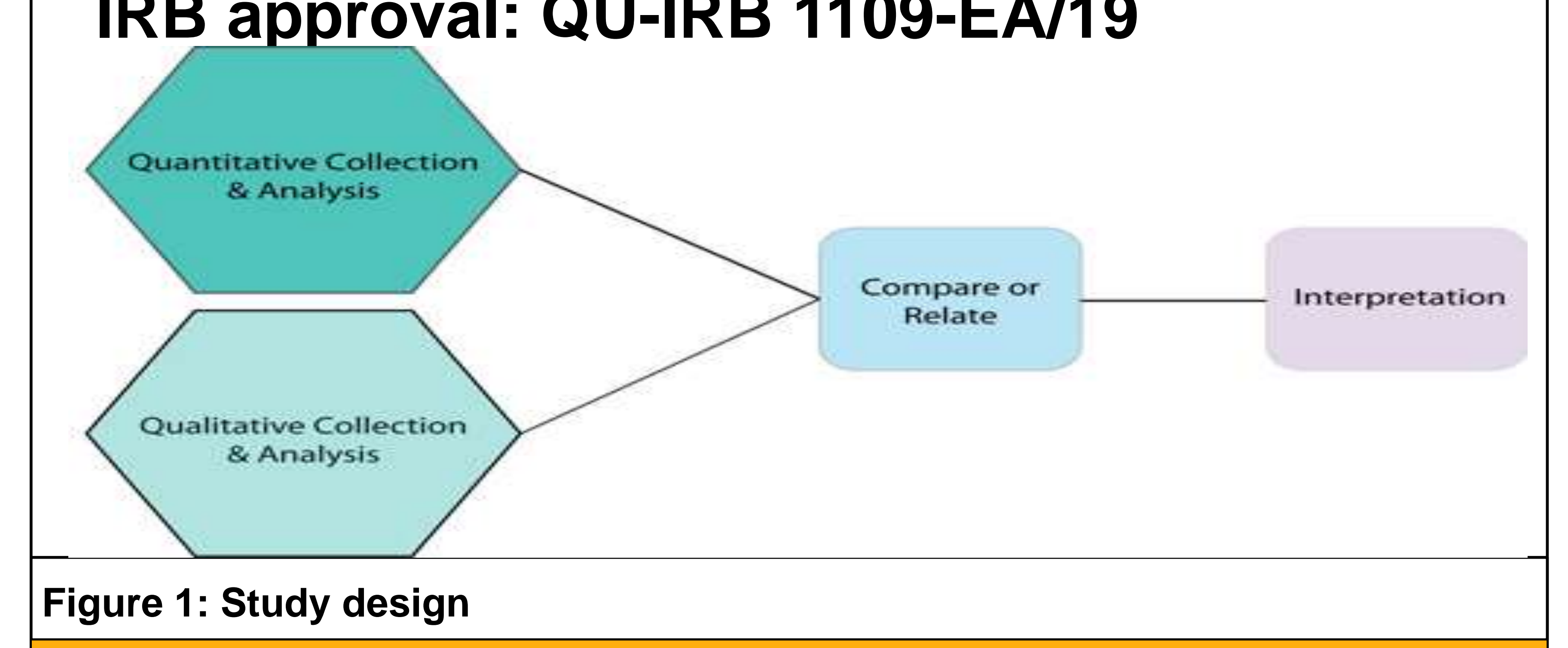

Acknowledgment

This study was funded by Qatar University Grant: QUST-2-CPH-2019-6

\section{Results}

Quantitative results

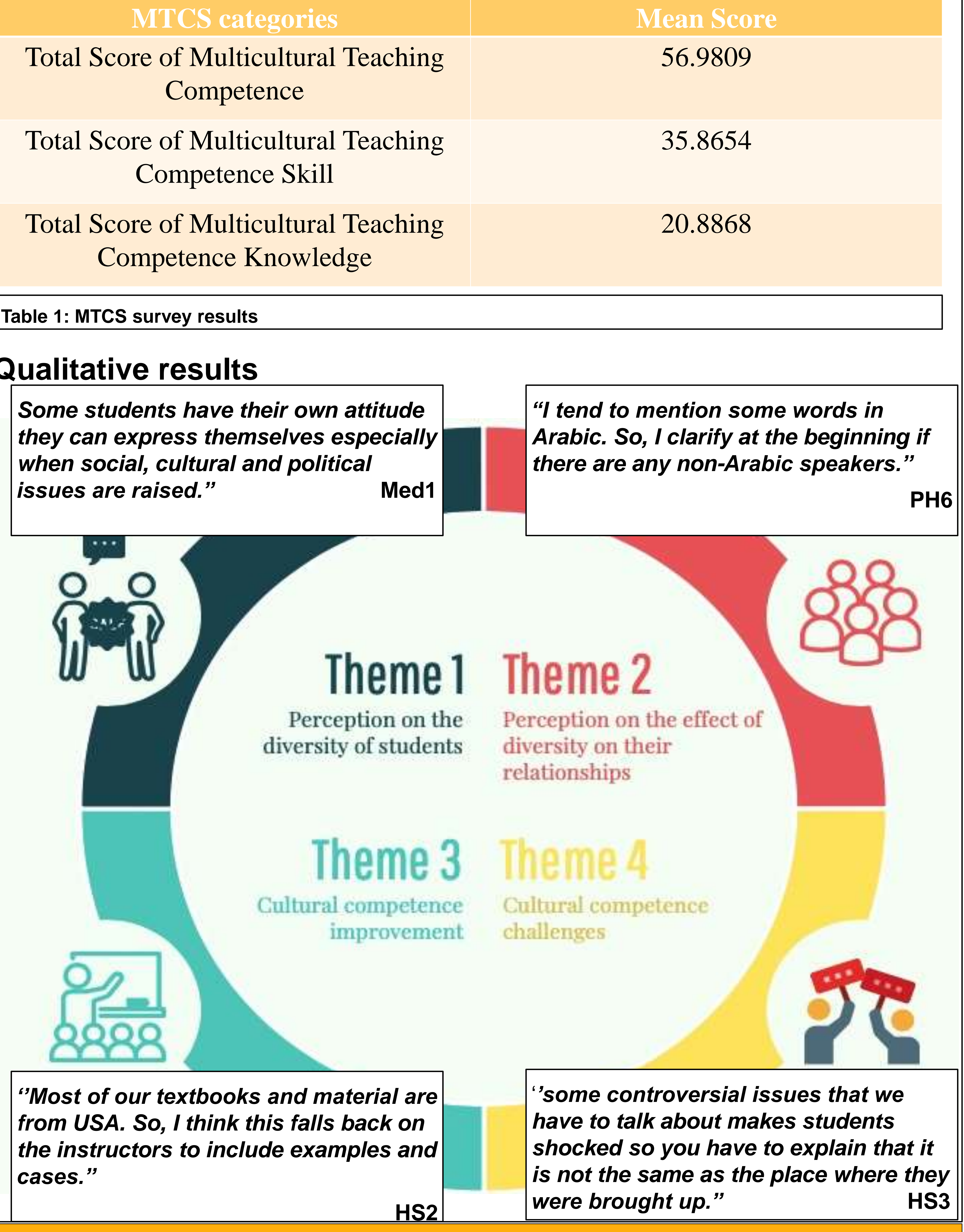

\section{항 Conclusions}

The results suggested a positive behavior towards multicultural teaching demonstrating that faculty members in QU's Health Cluster are generally knowledgeable and skilled with regards to the multicultural teaching.

Faculty members in QU's Health Cluster indicated that cultural diversity can influence the way faculty and students deal with each other, the delivery of scientific materials and the future practice of health care professionals.

Faculty members suggested having more focus on cultural heritage and values during the introductory orientation they receive when they join QU.

Future research should focus on understanding the influence of cultural diversity on students' skills and learning experiences.

\section{References}

(1)What Is Globalization? Peterson Institute for International Economics. Available from: https://www.piie.com/microsites/globalization/what-is-globalization.html

(2) Saha S, Beach MC, Cooper LA. Patient centeredness, cultural competence and healthcare quality. Journal of the National Medical Association. U.S. National Library of Medicine; 2008. Available from:

(3)Creswell JW, L. PCV. Designing and conducting mixed methods research. Los Angeles etc.: SAGE; 2018. 